\title{
Contornos da produção acadêmica sobre gestão democrática do ensino público em teses e dissertações da área da educação (1996-2015)
}

\author{
Profile of academic production on democratic management of public schools in \\ theses and dissertations on education (1996-2015) \\ Contornos de la producción académica sobre gestión democrática de la \\ enseñanza pública en tesis y disertaciones del área de la educación (1996-2015)
}

Resumo: $O$ artigo tem por objetivo refletir a respeito das características da produção acadêmica sobre gestão democrática do ensino público na Educação Básica, compreendidas as teses e dissertações da área da Educação publicadas no período de 1996 a 2015, constantes no Catálogo de Teses e Dissertações da Capes. Os dados foram submetidos a análise quanti-qualitativa e os resultados evidenciam um impulso no número de trabalhos no último Quadriênio do período, prevalecendo enfoques na interface com as políticas educacionais e em experiências concretas de gestão. Conclui que a dinâmica e o perfil das produções sugerem uma progressiva projeção do tema apoiada na dimensão política da gestão educacional.

Palavras-chave: Gestão democrática; ensino público; educação básica; produção acadêmica.

\begin{abstract}
The purpose of this article is to think over the features of academic production on the democratic management of public schools in basic education, including theses and dissertations on Education published between 1996 and 2015, referred in the Theses and Dissertations Catalog of Capes. Data were submitted to quantitative and qualitative analysis and results imply an increase in the number of papers in the last four years of the analyzed period, with prevailing approaches on educational policies and concrete management experiences. It concludes that the dynamics and profile of the papers suggest a growing relevance of the theme supported by the political dimension of educational management.
\end{abstract}

Keywords: Democratic management; public education; basic education; academic production.

Resumen: El artículo tiene por objetivo reflexionar sobre las características de la producción académica sobre la gestión democrática de la enseñanza pública en la educación básica, incluyendo las tesis y disertaciones del área de la Educación, publicadas entre 1996 y 2015, referidas en el Catálogo de Tesis y Disertaciones de Capes. Los datos se sometieron a análisis cantitativos y calitativos y los resultados 
evidencian un aumento en el número de trabajos en los últimos cuatro años del período analizado, con enfoques prevalecientes sobre las políticas educativas y las experiencias de gestión concretas. Concluye que la dinámica y el perfil de las producciones sugieren una creciente proyección del tema respaldado en la dimensión política de la gestión educativa.

Palabras clave: Gestión democrática; enseñanza pública; Educación básica; Producción académica.

\section{INTRODUÇÃO}

No campo social, costumamos referir-nos à década de 80 do século XX como uma das mais promissoras em mobilizações para a construção de um projeto educacional, mobilizações essas situadas em um processo de disputa política pela redemocratização do país. Um tempo em que a bandeira da participação obteve grande impulso e que, conforme anota Nogueira (2015), oportunizou um processo de qualificação da atividade política, por meio do qual também fora tecida crítica contundente à ideia de política como atividade exclusiva de políticos profissionais.

Nesse tempo de disputas - inclusive pelo significado de democracia no país - a gestão educacional também adquiriu notoriedade. Por um lado, em razão de se tratar de um domínio central da política pública para a consecução de objetivos educacionais; por outro, pelo crescente processo de produção do conhecimento sobre o tema.

A concepção de gestão ensaiada no contexto descrito guardava estreita conexão com as questões sociais e econômicas vividas no país (WEFFORT, 1984), bem como correspondência com reivindicações em defesa da implantação de canais de participação e de mecanismos de controle social perspectivados no contexto da relação entre Estado e sociedade. A expressão 'gestão democrática', que, antes de se tornar corrente no meio acadêmico, já era utilizada pelos movimentos sociais da época (PINHEIRO, 2015), resultou incorporada à Constituição Federal de 1988 (BRASIL, 1988), que a firmou como princípio nos seguintes termos: "gestão democrática do ensino público, na forma da lei" (art. 206, VI). Na opinião de Cury (2005), uma medida admirável para a vida democrática no âmbito dos sistemas de ensino e escolas.

Assim posto, temos que uma leitura crítico-compreensiva da gestão educacional, para além de sua abordagem como campo de formulação e implementação de políticas de educação e de organização do trabalho educativo, requer que se tenha em conta a orientação política por ela informada, assim como o sentido que assume essa orientação na dinâmica das relações político-sociais. Em um contexto de crescente projeção de uma perspectiva democrática sobre o 
tema - ainda que não somente - assim como de contrastes despontados da relação dessa perspectiva com políticas e práticas de gestão educacional levadas a efeito na atualidade, diversas questões vêm sendo submetidas a estudos e pesquisas na área da Educação.

Atentos a esse cenário, o objetivo deste trabalho é refletir a respeito das características da produção acadêmica sobre gestão democrática do ensino público na Educação Básica, compreendidas as teses e dissertações da área da Educação publicadas no período de 1996 a 2015, constantes em base de dados da Coordenação de Aperfeiçoamento de Pessoal de Nível Superior (Capes). Trata-se de pôr à mostra um panorama e o que focalizam esses estudos e investigações, ${ }^{1}$ buscando realçar os interesses pulsantes na comunidade acadêmica a respeito desse tema, consoante à ideia de pesquisas sobre pesquisas (FERNANDES; MOROSINI, 2014).

Para tanto, a base empírica consistiu na produção acadêmica relacionada à temática, constante no Catálogo de Teses e Dissertações da Capes. O levantamento foi realizado no período de outubro de 2017 a julho de 2018, tendo compreendido duas etapas básicas. Na primeira, foi procedida a identificação do conjunto inicial de trabalhos, observados os seguintes critérios, operados por meio do acionamento de filtros: estar vinculado à área das Ciências Humanas; estar submetido à avaliação da área da Educação; e conter, no resumo, o termo 'gestão'.

A segunda etapa da pesquisa destinou-se à seleção de trabalhos com base no critério da focalização de temas relacionados à gestão da educação básica. Ato contínuo, o conjunto resultante foi submetido a um enquadramento em cinco categorias temáticas, cuja sistematização consistiu em etapa preliminar à construção de sínteses analíticas acerca dos enfoques conferidos ao tema 'gestão democrática do ensino público na educação básica'. Também como parte da segunda etapa, delineamos um conjunto de outros elementos característicos na produção acadêmica identificada, por meio do qual fosse possível indicar tendências na produção do conhecimento sobre a temática, além de características dos trabalhos acadêmicos levantados.

De acordo com o exposto, são lançadas, inicialmente, algumas reflexões em torno do campo temático enfocado e de sua contextualização enquanto objeto de estudo na atualidade. $\mathrm{Na}$ sequência, abordamos o processo de pesquisa e, fundamentalmente, os resultados do levantamento, então submetidos

1 A pesquisa da qual resulta o presente trabalho filia-se a um projeto em rede, que conta com o apoio do Conselho Nacional de Desenvolvimento Científico e Tecnológico (CNPq). 
à análise orientada por uma abordagem quanti-qualitativa, em sentido de complementaridade mútua (CHIZZOTTI, 1991). Na última seção são tecidas considerações com vistas a uma síntese conclusiva.

\section{GESTÃO DEMOCRÁTICA DO ENSINO PÚBLICO: ALGUMAS NOTAS}

Partindo da ideia de democracia como processo (e não como estado), sobressai o termo 'democratização', tendo em vista que a realização daquela somente se dá na combinação entre "a socialização da participação política com a socialização do poder [...]" (COUTINHO, 2003, p. 17, grifo dos autores). Nessa direção, entendemos a participação política como recurso fundamental à democratização da gestão da educação, sendo devido reconhecer a concorrência de fatores políticos, econômicos e sociais que buscam simplificá-la, especialmente, em seu teor político. Seguindo as reflexões de Nogueira (2015), um exemplo dessa simplificação é justamente o comprometimento da qualidade da representação política oportunizada, frequentemente expressa na fórmula participação com controle do poder de decisão.

Do cotejamento dos referenciais dessas reflexões com a realidade informada pelo contexto político brasileiro, as questões e tensões que se armam são muitas e complexas. Consideremos, por exemplo, que nos anos de 1980, caracterizados pela mobilização da sociedade em prol da democratização da educação, a participação da sociedade na gestão desse bem público também integrava a pauta das reivindicações. Tratava-se, segundo Krawczyk (2008), da defesa da participação como expressão da cidadania ativa. Ao certo, também se tratava de atitude de denúncia e conclamação ao enfrentamento dos valores autoritários, típicos na cultura política brasileira de cariz patrimonialista (FAORO, 1987) e que, ao longo do tempo, temperam retrocessos e aberturas. O balanço de Ianni (2004) sobre esses retrocessos e aberturas no século passado, cuja resultante não foi o favorecimento dos interesses da maior parte do povo, constitui mostra importante da mencionada complexidade.

Importa destacar, ainda assim, que a mobilização da sociedade também favoreceu que fossem tornadas mais evidentes as consequências de uma frágil qualidade política do controle social exercido pela sociedade sobre o Estado, deixando mais explícito o valor da participação na construção da realidade político-social (BORDENAVE, 1985). Na esteira dessa inferência, concordamos que "o modelo institucional predominante, os atores políticos envolvidos e os respectivos estilos de fazer política" (AVELAR, 1996, p. 46) não podem passar ao largo de análises referentes a uma política endereçada à democratização da gestão 
educacional. A adesão a uma concepção de democracia como "um projeto que se esgota na 'normalização' das instituições políticas"” (BORON, 2002, p. 7) é, a nosso ver, outro aspecto que não deve fugir às análises sobre o tema.

No curso do tempo histórico, em vista dos desdobramentos políticos e econômicos ocorridos na década de 90 , assistimos à ascensão de contundentes apelos à modernização da gestão pública, segundo fundamentos da gestão privada. De acordo com Dardot e Laval (2016, p. 227), 'a nova gestão' identificase, basicamente, com "o desenvolvimento da contratualização das relações sociais, a descentralização das negociações entre assalariados e o patronato [...] a concorrência [...] a normalização pela imposição generalizada de padrões de qualidade e o crescimento da avaliação individualizada dos resultados."

No âmbito da educação, a ascensão da 'nova gestão' afigurará o que se tem denominado de novo gerenciamento educativo. Segundo Freitas (2007), tratase da introdução de práticas empresariais de controle e prescrição que informam a emergência de uma política administrativa gerencial. Diferentemente do triunfo da democracia, o fim político dessa ascensão, de acordo com Laval (2004, p. 261), é o de "fazer da escola uma máquina eficaz a serviço da competitividade econômica."

Assinalado o contraste dessa perspectiva com o projeto de educação e gestão democrática plantado no final do século passado, importa destacar que as políticas educacionais postas em marcha nos anos de 1990 foram evidenciando que o objetivo de democratização da educação passou a ser o de "imprimir maior racionalidade à gestão [...] [convergindo] para novos modelos de gestão do ensino público, modelos esses calcados em formas mais flexíveis, participativas e descentralizadas de administração de recursos e das responsabilidades." (OLIVEIRA, 2008, p. 131). Dentre outras, a autonomização da escola pública, inscrita em novo modelo de regulação (FELDFEBER, 2009; NARDI, 2015), constitui marca desses novos modelos de gestão, marca esta destacada em paralelo a uma corrente de denúncias sobre a ineficiência da escola, razão pela qual devesse assumir mecanismos eficientes de gerenciamento, mormente em sintonia com o objetivo de "produzir mais com menor custo." (FONSECA; OLIVEIRA, 2009, p. 235, grifo dos autores).

2

Segundo Boron (2002), para os tributários dessa perspectiva (dente os quais figuram segmentos da esquerda latino-americana e tradicionais representantes das posições neoconservadoras), "[...] a gigantesca empresa de instaurar a democracia se reduz à criação e institucionalização de uma simples ordem política isto é, um sistema de regras do jogo que faz abstração de seus conteúdos éticos e da natureza profunda dos antagonismos sociais - e que só coloca problemas de governabilidade e eficácia administrativa.” (p. 7). 
No que se refere ao plano das bases normativas vigentes, o princípio da 'gestão democrática do ensino público', firmado no art. 206 da Constituição Federal de 1988, constitui o referencial primeiro para o delineamento de qualquer outra norma sobre a matéria.

Os dispositivos encontrados na Lei de Diretrizes e Bases da Educação Nacional (LDB), por sua vez, são indicativos de que não houve maiores avanços na definição de diretrizes mais específicas sobre o tema. Nessa lei, o conteúdo principal quanto à matéria pode ser encontrado no seu art. $3^{\circ}$, inciso VII, que reafirma o princípio constitucional da gestão democrática do ensino público, submetendo-o à regulação infraconstitucional nos termos definidos pela própria Lei 9394/96 (BRASIL, 1996) e pela legislação vinculada aos sistemas de ensino. No âmbito da lei federal, a regulamentação repousa, mais especificamente, nos seguintes dispositivos:

Art. 14. Os sistemas de ensino definirão as normas da gestão democrática do ensino público na Educação Básica, de acordo com as suas peculiaridades e conforme os seguintes princípios: [...]I - participação dos profissionais da educação na elaboração do projeto pedagógico da escola[...] II - participação das comunidades escolar e local em conselhos escolares ou equivalentes. [...] Art. 15. Os sistemas de ensino assegurarão às unidades escolares públicas de educação básica que os integram progressivos graus de autonomia pedagógica e administrativa e de gestão financeira, observadas as normas gerais de direito financeiro público.

Dentre outras medidas em escala nacional que, desde a LDB, visaram normatizar o princípio da 'gestão democrática do ensino público na Educação Básica', destacamos a Lei no. 13.005, de 25 de junho de 2014 (BRASIL, 2014), que aprovou o Plano Nacional de Educação (PNE) para o período 2014-2024. Essa lei reforçou o encaminhamento da normatização da matéria, tendo fixado o prazo de dois anos para que os estados, o Distrito Federal e os municípios disciplinassem a matéria no âmbito dos respectivos sistemas de ensino.

Ainda assim, conforme demonstra Nardi (2016), entre a promulgação da LDB e a aprovação do atual PNE, várias iniciativas despontaram na esfera legislativa federal. Segundo o autor, foram iniciativas que visaram a "assegurar que determinadas opções e práticas endereçadas à democratização da gestão do ensino público [...] [obtivessem] selo formal" (NARDI, 2016, p. 33), vezes coerentes com as velhas bandeiras progressistas, vezes em direção a modelos técnico-gerenciais de gestão escolar. Sobrestadas na fase final do mencionado período, em vista do rumo que assumia o PNE, as propostas subjacentes a tais iniciativas perderam suas vagas na definição formal das bases normativas. Isso porque o PNE 2014- 
2024 retomara referencialmente o que há mais de duas décadas fora firmado na LDB: a incumbência dos sistemas de ensino na definição de normas da 'gestão democrática do ensino público na Educação Básica'.

Nesse contexto complexo de disputas por diferentes projetos de educação e de gestão educacional, tanto as apostas na democratização quanto as circunstâncias que têm patrocinado avanços e retrocessos nesse domínio continuam mobilizando a inclusão da 'gestão democrática do ensino público' na agenda de pesquisadores da área, do que resultam novas e atualizadas oportunidades de acesso ao conteúdo de análises úteis ao desvelamento de questões que rondam esse tema.

Atentos a esse contexto, passemos à caracterização da produção acadêmica sobre gestão democrática do ensino público na Educação Básica, compreendidas as teses e dissertações da área da Educação, do período de 1996 a 2015, constantes na base de dados da Capes.

\section{CARACTERIZAÇÃO DA PRODUÇÃO ACADÊMICA COLIGIDA: TESES E DISSERTAÇÕES}

Conforme referido, a primeira etapa da pesquisa foi aberta pelo processo de levantamento das teses e dissertações, realizado entre outubro de 2017 e julho de 2018. A identificação dos trabalhos, ocorrida por meio de filtros aplicados à base dos dados, foi guiada pela seleção das produções vinculadas à área das Ciências Humanas e programas de pós-graduação submetidos à avaliação da área da Educação, critério este possibilitado pela funcionalidade da base de dados e compatível com o estabelecimento do recorte de trabalhos da área. Após o levantamento, a providência seguinte consistiu na verificação da presença do termo 'gestão' no corpo do resumo de cada trabalho.

Das medidas deflagradas no âmbito da primeira etapa da pesquisa, resultou a identificação inicial do conjunto de 4.183 trabalhos acadêmicos, acessados mediante a aplicação dos filtros referentes à vinculação à área da Educação, compreendendo o acumulado do período 1996 a 2015. Quando retratados segundo disposição anual, os dados evidenciam uma projeção significativa do número de trabalhos, conforme ilustra o Gráfico 1. 


\section{Gráfico 1 - Produção acadêmica da área da Educação (teses e}

dissertações) identificada por meio do descritor gestão - Brasil 1996 a 2015

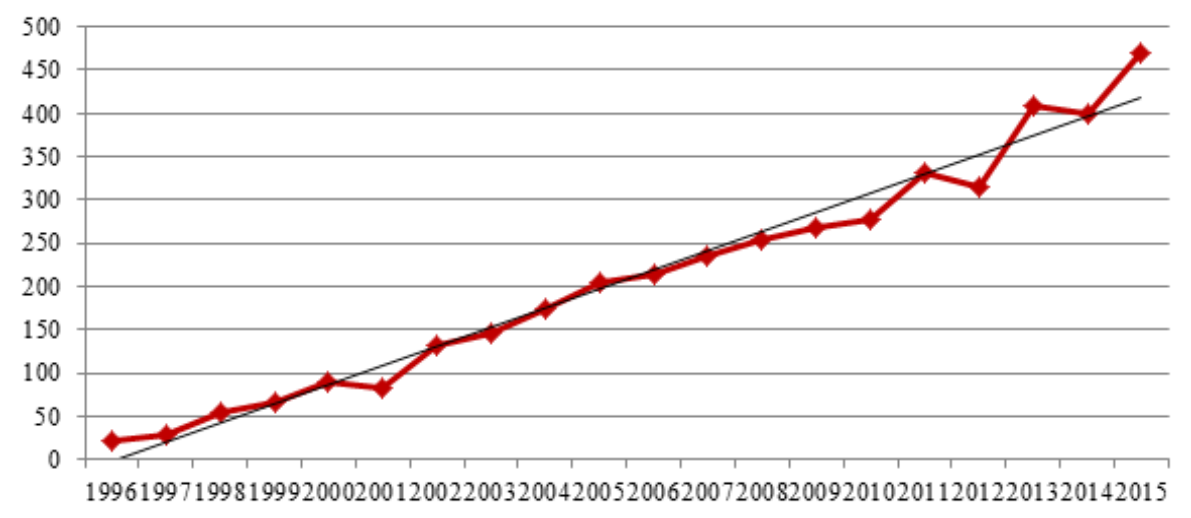

Fonte: Elaboração dos autores com base no Catálogo de Teses e Dissertações - Capes (2018).

De acordo com o gráfico, partindo de um quantitativo de 21 trabalhos, em 1996, e tendo alcançado 331 em 2011, os anos seguintes foram caracterizados por alternâncias anuais entre pequenas quedas e impulsos significativos. Conforme evidencia a linha de tendência, essas alternâncias representam, praticamente, a preservação do curso de ascensão do número de trabalhos no período coberto pela pesquisa.

Ao ser submetido ao crivo que visou à identificação de trabalhos relacionados com o tema gestão da Educação Básica, o conjunto inicial de produções acadêmicas foi diminuído em $53 \%$, ainda que mantida a característica de crescimento progressivo ao longo do período. O Gráfico 2 ilustra esse comportamento quantitativo, correlacionando-o com o conjunto inicial, de que dispõe o gráfico anterior. 


\section{Gráfico 2 - Produção acadêmica da área da Educação (teses \\ e dissertações) identificada por meio do descritor gestão e do enquadramento na categoria geral gestão da educação básica - Brasil 1996 a 2015}

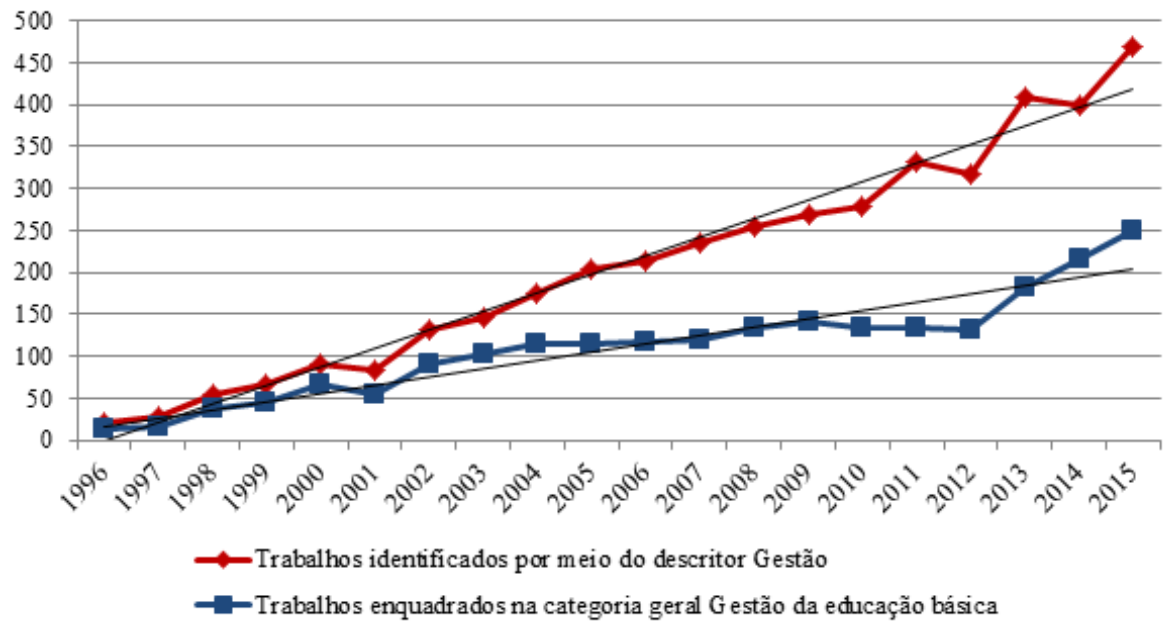

Fonte: Elaboração dos autores com base no Catálogo de Teses e Dissertações - Capes (2018).

Afora o crescimento progressivo, importa destacar um ciclo de ligeira queda no número de trabalhos sobre 'gestão da Educação Básica', datados de 2009 a 2012, seguido de outro ciclo com importante crescimento, este último estendido até o final do período pesquisado. De forma geral, fica evidente que a presença do tema em produções acadêmicas da área, ao longo do período enfocado, obteve uma projeção até o ano de 2004, mantendo-se na pauta dos estudos, com certa estabilidade, até 2012. Conforme mencionado, o triênio 2013-2015 demarca um impulso importante no número de trabalhos publicados, mais precisamente, um incremento de $90,8 \%$, razão pela qual cerca de 30\% dos trabalhos identificados são desse triênio.

Ainda no âmbito da primeira etapa da pesquisa, a atividade seguinte compreendeu a sistematização dos dados relativos aos 2.216 trabalhos cujas temáticas focalizam ou incluem a 'gestão da Educação Básica'. Nesse processo, foi constituído um banco de dados que possibilitou a organização do material em duas formas: (1) segundo o ano de publicação, contendo título, autor, resumo, palavras-chave, nome do programa de pós-graduação, instituição de educação 
superior, região geográfica, estado da federação e categoria temática afim; e (2) segundo a categoria temática, contendo os demais elementos descritos para a primeira forma.

As categorias temáticas foram definidas a priori pela equipe de pesquisa, considerando sua experiência na lida com questões contemporâneas atinentes à 'gestão da Educação Básica', submetidas a estudos anteriores. Por um lado, essas categorias garantem a cobertura de um conjunto de domínios típicos e frequentes em estudos da área, sejam eles unitários ou associados; por outro, preservam razoável grau de abrangência, útil à construção de análises que possam espelhar melhor a diversidade de objetos, problemáticas e circunstâncias contemplados pelos trabalhos acadêmicos que enfocam ou transitam pela referida temática. O Gráfico 3 traz a identificação dessas categorias e ilustra os resultados do enquadramento dos 2.216 trabalhos acadêmicos.

\section{Gráfico 3 - Produção acadêmica da área da Educação (teses e dissertações), enquadrada por categoria temática - Brasil 1996 a 2015}

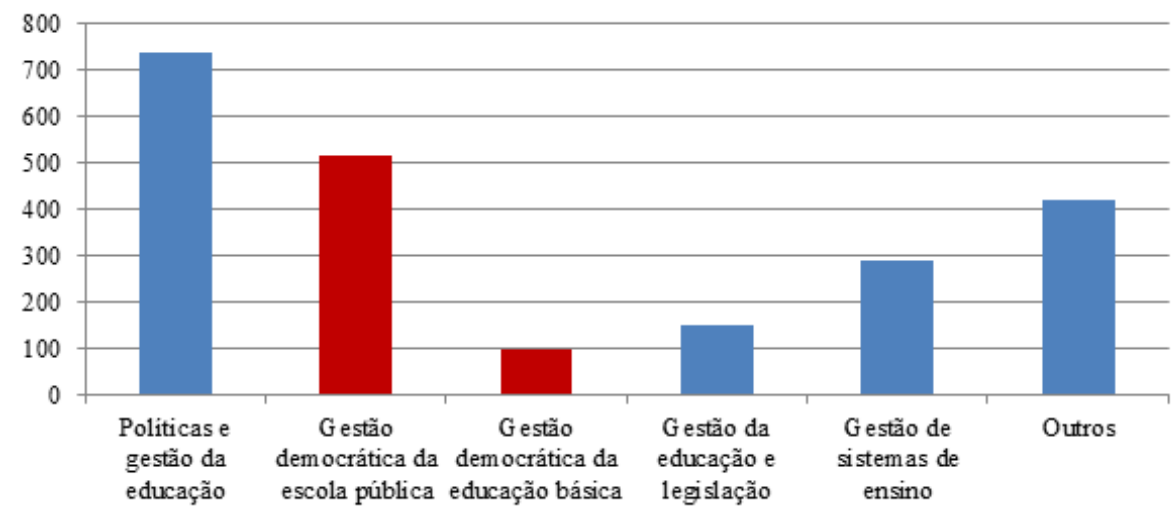

Fonte: Elaboraão dlos Elaboração dos autores com base no Catálogo de Teses e Dissertações Capes (2018).

Os dados ilustrados no gráfico evidenciam que o tema 'gestão da Educação Básica' tem sido abordado com maior recorrência na relação ou interface com o das políticas educacionais e da democratização da gestão, nesse caso destacando-se a figura da escola pública. A se considerar a presença do tema democratização, independentemente do campo enfocado (escola ou Educação 
Básica em sentido amplo), o quantitativo de trabalhos enquadrados nas categorias 2 e $3^{3}$ - alvos principais da pesquisa - representa cerca de um terço do universo de teses e dissertações do conjunto.

Outro aspecto de caracterização geral do conjunto de trabalhos acadêmicos diz respeito à distribuição geográfica segundo a sede das instituições de ensino superior a que se vinculam. Os dados da Tabela 1 permitem verificar a distribuição dos 2.216 trabalhos acadêmicos segundo a região e respectivas unidades da federação.

\section{Tabela 1 - Número de trabalhos, por categoria temática, segundo região} geográfica e unidade federativa - 1996 a 2015

\begin{tabular}{|c|c|c|c|c|c|c|c|}
\hline \multirow{2}{*}{$\begin{array}{l}\text { Regiões/ unidades } \\
\text { federativas a que } \\
\text { se vinculam os } \\
\text { trabalhos }\end{array}$} & \multicolumn{7}{|c|}{ Trabalhos por categoria temática } \\
\hline & $\begin{array}{l}\text { 1. Políticas } \\
\text { e gestão da } \\
\text { educação }\end{array}$ & $\begin{array}{l}\text { 2. Gestão } \\
\text { democrática } \\
\text { da escola } \\
\text { pública }\end{array}$ & $\begin{array}{c}\text { 3. Gestão } \\
\text { democrática } \\
\text { da Educação } \\
\text { Básica }\end{array}$ & $\begin{array}{l}\text { 4. Gestão } \\
\text { da } \\
\text { educação e } \\
\text { legislação }\end{array}$ & $\begin{array}{l}\text { 5. Gestão } \\
\text { de sistemas } \\
\text { de ensino }\end{array}$ & 6. Outros & Total \\
\hline CENTRO-OESTE & 94 & 77 & 9 & 17 & 31 & 40 & 268 \\
\hline $\begin{array}{l}\text { Distrito Federal } \\
\text { (DF) }\end{array}$ & 48 & 40 & 2 & 9 & 11 & 21 & 131 \\
\hline Goiás (GO) & 16 & 8 & 3 & 0 & 9 & 11 & 47 \\
\hline Mato Grosso (MT) & 5 & 18 & 2 & 0 & 4 & 4 & 33 \\
\hline $\begin{array}{l}\text { Mato Grosso do Sul } \\
\text { (MS) }\end{array}$ & 25 & 11 & 2 & 8 & 7 & 4 & 57 \\
\hline NORDESTE & 104 & 88 & 17 & 24 & 46 & 68 & 347 \\
\hline Alagoas (AL) & 6 & 6 & 1 & 1 & 2 & 1 & 17 \\
\hline Bahia (BA) & 25 & 20 & 7 & 8 & 14 & 18 & 92 \\
\hline Ceará (CE) & 16 & 11 & 4 & 2 & 8 & 17 & 58 \\
\hline Maranhão (MA) & 5 & 4 & 0 & 2 & 2 & 1 & 14 \\
\hline Paraíba (PB) & 13 & 12 & 2 & 1 & 3 & 3 & 34 \\
\hline Pernambuco (PE) & 11 & 15 & 2 & 6 & 6 & 12 & 52 \\
\hline Piauí (PI) & 6 & 4 & 0 & 0 & 3 & 4 & 17 \\
\hline $\begin{array}{c}\text { Rio Grande do } \\
\text { Norte (RN) }\end{array}$ & 17 & 13 & 1 & 4 & 7 & 11 & 53 \\
\hline Sergipe (SE) & 5 & 3 & 0 & 0 & 1 & 1 & 10 \\
\hline NORTE & 18 & 25 & 2 & 10 & 14 & 10 & 79 \\
\hline Amazonas (AM) & 6 & 12 & 1 & 3 & 2 & 5 & 29 \\
\hline Pará (PA) & 11 & 11 & 1 & 4 & 12 & 4 & 43 \\
\hline Rondônia (RO) & 1 & 2 & 0 & 3 & 0 & 1 & 7 \\
\hline
\end{tabular}


Tabela 1 - Número de trabalhos, por categoria temática, segundo região geográfica e unidade federativa - 1996 a 2015

\begin{tabular}{|c|c|c|c|c|c|c|c|}
\hline \multirow[b]{2}{*}{$\begin{array}{l}\text { Regiões/ unidades } \\
\text { federativas a que } \\
\text { se vinculam os } \\
\text { trabalhos }\end{array}$} & \multicolumn{7}{|c|}{ Trabalhos por categoria temática } \\
\hline & $\begin{array}{l}\text { 1. Políticas } \\
\text { e gestão da } \\
\text { educação }\end{array}$ & $\begin{array}{l}\text { 2. Gestão } \\
\text { democrática } \\
\text { da escola } \\
\text { pública }\end{array}$ & $\begin{array}{c}\text { 3. Gestão } \\
\text { democrática } \\
\text { da Educação } \\
\text { Básica }\end{array}$ & $\begin{array}{l}\text { 4. Gestão } \\
\text { da } \\
\text { educação e } \\
\text { legislação }\end{array}$ & $\begin{array}{l}\text { 5. Gestão } \\
\text { de sistemas } \\
\text { de ensino }\end{array}$ & 6. Outros & Total \\
\hline SUDESTE & 395 & 239 & 45 & 65 & 142 & 202 & 1.088 \\
\hline Espírito Santo (ES) & 6 & 3 & 2 & 2 & 4 & 5 & 22 \\
\hline Minas Gerais (MG) & 142 & 35 & 8 & 18 & 31 & 56 & 290 \\
\hline Rio de Janeiro (RJ) & 50 & 28 & 2 & 10 & 19 & 26 & 135 \\
\hline São Paulo (SP) & 197 & 173 & 33 & 35 & 88 & 115 & 641 \\
\hline SUL & 127 & 86 & 26 & 34 & 58 & 103 & 434 \\
\hline Paraná (PR) & 39 & 27 & 8 & 10 & 22 & 30 & 136 \\
\hline Santa Catarina (SC) & 24 & 18 & 7 & 6 & 10 & 15 & 80 \\
\hline $\begin{array}{l}\text { Rio Grande do Sul } \\
\text { (RS) }\end{array}$ & 64 & 41 & 11 & 18 & 26 & 58 & 218 \\
\hline TOTAL & 738 & 515 & 99 & 150 & 291 & 423 & 2.216 \\
\hline$\%$ & 33,3 & 23,2 & 4,5 & 6,8 & 13,1 & 19,1 & 100 \\
\hline
\end{tabular}

Fonte: Elaboração dos autores com base no Catálogo de Teses e Dissertações - Capes (2018).

A distribuição geográfica da origem dos trabalhos acadêmicos realça as regiões Sudeste e Sul, embora esta última esteja mais próxima, em número de trabalhos, das regiões Nordeste e Centro-Oeste. Em se tratando dos trabalhos enquadrados nas categorias temáticas 2 e 3 , seguem realçadas as mesmas regiões, porém diminuída a diferença do número de trabalhos. Nessas regiões, destacamse os estados de São Paulo, Rio Grande do Sul, Bahia e o Distrito Federal, respectivamente.

Identificado o universo de trabalhos cujos enfoques se concentram na temática gestão democrática do ensino público na Educação Básica, ou a incluem, assim como a origem dos trabalhos nas diferentes unidades da federação, importa agora verificarmos sua distribuição ano a ano, ao longo do período coberto pela pesquisa. Os dados constam no Gráfico 4. 
Gráfico 4 - Produção acadêmica da área da Educação (teses e dissertações), enquadrada nas categorias temáticas 2 e 3 - Brasil 1996 a 2015

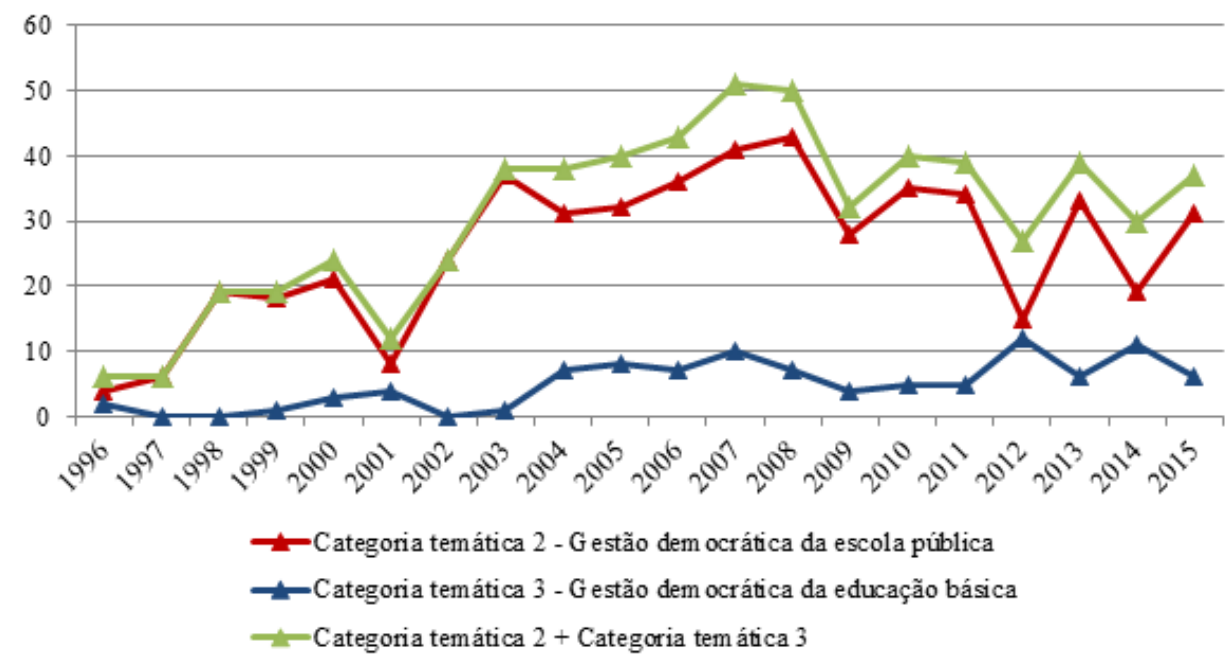

Fonte: Elaboração dos autores com base no Catálogo de Teses e Dissertações - Capes (2018).

Pelo exposto no gráfico, verificamos que, ao longo do tempo coberto pela pesquisa, prevalece a abordagem da temática na sua relação com a figura de escola pública. Se, por um lado, os trabalhos que têm em conta a Educação Básica em sentido ampliado representam somente 16\% da soma de trabalhos das duas categorias temáticas, por outro, tenderam a certa estabilidade ao longo tempo, destacadamente, a partir de 2004. Também cabe destacar a similitude no comportamento no número de produções das duas categorias entre 2004 e 2011, situação distinta da verificada em relação aos dois extremos do período. Tal comportamento denota, segundo nosso entendimento, a influência de fatores do contexto sócio-político e econômico na definição de temáticas e na eleição, pelos pesquisadores, de determinadas problemáticas de pesquisa.

Por fim, ainda sobre o retrato oportunizado pelo Gráfico 4, cabe destacar que as variações nas quantidades de teses e dissertações publicadas ao longo dos anos demarcam características distintas das apontadas no Gráfico 2, relativas aos trabalhos filiados à categoria geral 'gestão da Educação Básica', o que indica a presença de especificidades mobilizadoras da entrada em cena de estudos que envolvem o tema 'democratização da gestão'. 
Deslocadas as lentes para as categorias temáticas 2 e 3 (enfoque na 'gestão democrática'), um último aspecto de caracterização da produção acadêmica diz respeito à vinculação dos trabalhos com as respectivas instituições de educação superior, por localização geográfica, conforme dispõe a Tabela 2.

\section{Tabela 2 - Número de trabalhos acadêmicos com enfoque na 'gestão democrática' (categorias 2 e 3), segundo região geográfica, unidade federativa e instituição de educação superior - 1996 a 2015}

\begin{tabular}{|c|c|c|c|}
\hline \multirow{2}{*}{\multicolumn{2}{|c|}{$\begin{array}{l}\text { Regiões/unidades federativas das publicações / } \\
\text { instituição de educação superior }\end{array}$}} & \multicolumn{2}{|c|}{$\begin{array}{c}\text { Trabalhos acadêmicos (teses e } \\
\text { dissertações) }\end{array}$} \\
\hline & & Número & $\%$ \\
\hline \multicolumn{2}{|r|}{ CENTRO-OESTE } & 87 & \multirow{9}{*}{14,2} \\
\hline \multirow{2}{*}{ Distrito Federal (DF) } & Universidade de Brasília & 21 & \\
\hline & Universidade Católica de Brasília & 21 & \\
\hline \multirow{2}{*}{ Goiás (GO) } & Pontifícia Universidade Católica de Goiás & 7 & \\
\hline & Universidade Federal de Goiás & 4 & \\
\hline \multirow{2}{*}{ Mato Grosso (MT) } & Universidade do Estado do Mato Grosso & 1 & \\
\hline & Universidade Federal do Mato Grosso & 20 & \\
\hline \multirow{2}{*}{$\begin{array}{l}\text { Mato Grosso do Sul } \\
\text { (MS) }\end{array}$} & Universidade Católica Dom Bosco & 4 & \\
\hline & Universidade Federal do Mato Grosso do Sul & 9 & \\
\hline \multicolumn{2}{|r|}{ NORDESTE } & 104 & \multirow{15}{*}{16,9} \\
\hline Alagoas (AL) & Universidade Federal de Alagoas & 7 & \\
\hline \multirow{4}{*}{ Bahia (BA) } & Universidade Estadual de Feira de Santana & 1 & \\
\hline & Universidade Estadual do Sudoeste da Bahia & 1 & \\
\hline & Universidade Federal da Bahia & 15 & \\
\hline & Universidade do Estado da Bahia & 10 & \\
\hline \multirow{2}{*}{ Ceará (CE) } & Universidade Federal do Ceará & 12 & \\
\hline & Universidade Estadual do Ceará & 2 & \\
\hline Maranhão (MA) & Universidade Federal do Maranhão & 4 & \\
\hline Paraíba (PB) & Universidade Federal da Paraíba & 14 & \\
\hline Pernambuco (PE) & Universidade Federal de Pernambuco & 17 & \\
\hline Piauí (PI) & Universidade Federal do Piauí & 4 & \\
\hline \multirow{2}{*}{$\begin{array}{l}\text { Rio Grande do Norte } \\
\text { (RN) }\end{array}$} & Universidade do Estado do Rio Grande do Norte & 1 & \\
\hline & Universidade Federal do Rio Grande do Norte & 13 & \\
\hline Sergipe (SE) & Universidade Federal de Sergipe & 3 & \\
\hline
\end{tabular}




\section{Tabela 2 - Número de trabalhos acadêmicos com enfoque na 'gestão democrática' (categorias 2 e 3), segundo região geográfica, unidade federativa e instituição de educação superior - 1996 a 2015}

\begin{tabular}{|c|c|c|c|}
\hline \multirow{2}{*}{\multicolumn{2}{|c|}{$\begin{array}{l}\text { Regiões/unidades federativas das publicações / } \\
\text { instituição de educação superior }\end{array}$}} & \multicolumn{2}{|c|}{$\begin{array}{c}\text { Trabalhos acadêmicos (teses e } \\
\text { dissertações) }\end{array}$} \\
\hline & & Número & $\%$ \\
\hline \multicolumn{2}{|r|}{ NORTE } & 27 & \multirow{5}{*}{4,4} \\
\hline Amazonas (AM) & Universidade Federal do Amazonas & 13 & \\
\hline \multirow{2}{*}{ Pará (PA) } & Universidade do Estado do Pará & 3 & \\
\hline & Universidade Federal do Pará & 9 & \\
\hline Rondônia (RO) & Universidade Federal de Rondônia & 2 & \\
\hline \multicolumn{2}{|r|}{ SUDESTE } & 284 & \multirow{26}{*}{46,3} \\
\hline Espírito Santo (ES) & Universidade Federal do Espírito Santo & 5 & \\
\hline \multirow{8}{*}{$\begin{array}{c}\text { Pontifícia Universidade } \\
\text { Católica de Minas } \\
\text { Gerais }\end{array}$} & Pontifícia Universidade Católica de Minas Gerais & 2 & \\
\hline & Universidade do Vale do Sapucaí & 1 & \\
\hline & Universidade Federal de Juiz de Fora & 16 & \\
\hline & Universidade Federal de Minas Gerais & 11 & \\
\hline & Universidade Federal de Uberaba & 2 & \\
\hline & Universidade Federal de Uberlândia & 9 & \\
\hline & Universidade Federal do Triângulo Mineiro & 1 & \\
\hline & Universidade Federal de Viçosa & 1 & \\
\hline \multirow{6}{*}{ Rio de Janeiro (RJ) } & Pontifícia Universidade Católica do Rio de Janeiro & 4 & \\
\hline & Universidade Católica de Petrópolis & 2 & \\
\hline & Universidade do Estado do Rio de Janeiro & 7 & \\
\hline & Universidade Estácio de Sá & 1 & \\
\hline & Universidade Federal Fluminense & 10 & \\
\hline & Universidade Federal do Estado do Rio de Janeiro & 6 & \\
\hline \multirow{10}{*}{ São Paulo (SP) } & Centro Universitário Moura Lacerda & 4 & \\
\hline & Centro Universitário Salesiano de São Paulo & 4 & \\
\hline & Pontifícia Universidade Católica de Campinas & 3 & \\
\hline & Pontifícia Universidade Católica de São Paulo & 39 & \\
\hline & Universidade Católica de Santos & 5 & \\
\hline & Universidade Cidade de São Paulo & 5 & \\
\hline & Universidade de São Paulo & 19 & \\
\hline & Universidade Estadual de Campinas & 25 & \\
\hline & $\begin{array}{l}\text { Universidade Estadual Paulista Júlio de Mesquita } \\
\text { Filho }\end{array}$ & 9 & \\
\hline & $\begin{array}{l}\text { Universidade Estadual Paulista Júlio de Mesquita } \\
\text { Filho/Araraquara }\end{array}$ & 10 & \\
\hline
\end{tabular}




\section{Tabela 2 - Número de trabalhos acadêmicos com enfoque na 'gestão democrática' (categorias 2 e 3), segundo região geográfica, unidade federativa e instituição de educação superior - 1996 a 2015}

\begin{tabular}{|c|c|c|c|}
\hline \multirow{2}{*}{\multicolumn{2}{|c|}{$\begin{array}{l}\text { Regiões/unidades federativas das publicações / } \\
\text { instituição de educação superior }\end{array}$}} & \multicolumn{2}{|c|}{$\begin{array}{c}\text { Trabalhos acadêmicos (teses e } \\
\text { dissertações) }\end{array}$} \\
\hline & & Número & $\%$ \\
\hline \multicolumn{2}{|r|}{ SUDESTE } & 284 & \multirow{10}{*}{46,3} \\
\hline \multirow{9}{*}{ São Paulo (SP) } & $\begin{array}{l}\text { Universidade Estadual Paulista Júlio de Mesquita } \\
\text { Filho/Marília }\end{array}$ & 13 & \\
\hline & $\begin{array}{l}\text { Universidade Estadual Paulista Júlio de Mesquita } \\
\text { Filho/Presidente Prudente }\end{array}$ & 3 & \\
\hline & $\begin{array}{l}\text { Universidade Estadual Paulista Júlio de Mesquita } \\
\text { Filho/Rio Claro }\end{array}$ & 3 & \\
\hline & Universidade Metodista de Piracicaba & 10 & \\
\hline & Universidade Metodista de São Paulo & 13 & \\
\hline & Universidade Nove de Julho & 1 & \\
\hline & Universidade de Sorocaba & 4 & \\
\hline & Universidade do Oeste Paulista & 12 & \\
\hline & Universidade Federal de São Carlos & 24 & \\
\hline \multicolumn{2}{|r|}{ SUL } & 112 & \multirow{16}{*}{18,2} \\
\hline \multirow{7}{*}{ Paraná (PR) } & Pontifícia Universidade Católica do Paraná & 5 & \\
\hline & Universidade Estadual de Londrina & 1 & \\
\hline & Universidade Estadual de Maringá & 2 & \\
\hline & Universidade Estadual de Ponta Grossa & 3 & \\
\hline & Universidade Estadual do Oeste do Paraná & 2 & \\
\hline & Universidade Federal do Paraná & 11 & \\
\hline & Universidade Tuiuti do Paraná & 11 & \\
\hline \multirow{8}{*}{ Santa Catarina (SC) } & Universidade Federal de Santa Catarina & 8 & \\
\hline & Universidade do Estado de Santa Catarina & 1 & \\
\hline & Universidade do Extremo Sul Catarinense & 1 & \\
\hline & Universidade do Oeste de Santa Catarina & 2 & \\
\hline & Universidade do Planalto Catarinense & 2 & \\
\hline & Universidade do Vale do Itajaí & 2 & \\
\hline & Universidade Regional de Blumenau & 8 & \\
\hline & Universidade do Sul de Santa Catarina & 1 & \\
\hline
\end{tabular}




\section{Tabela 2 - Número de trabalhos acadêmicos com enfoque na 'gestão democrática' (categorias 2 e 3), segundo região geográfica, unidade federativa e instituição de educação superior - 1996 a 2015}

\begin{tabular}{|c|c|c|c|}
\hline \multirow{2}{*}{\multicolumn{2}{|c|}{$\begin{array}{l}\text { Regiões/unidades federativas das publicações / } \\
\text { instituição de educação superior }\end{array}$}} & \multicolumn{2}{|c|}{$\begin{array}{c}\text { Trabalhos acadêmicos (teses e } \\
\text { dissertações) }\end{array}$} \\
\hline & & Número & $\%$ \\
\hline & SUL & 112 & \multirow{8}{*}{18,2} \\
\hline \multirow{7}{*}{$\begin{array}{l}\text { Rio Grande do Sul } \\
\text { (RS) }\end{array}$} & Centro Universitário La Salle & 1 & \\
\hline & $\begin{array}{c}\text { Pontifícia Universidade Católica do Rio Grande } \\
\text { do Sul }\end{array}$ & 6 & \\
\hline & Universidade de Passo Fundo & 6 & \\
\hline & Universidade do Vale do Rio dos Sinos & 12 & \\
\hline & Universidade Federal de Pelotas & 4 & \\
\hline & Universidade Federal de Santa Maria & 8 & \\
\hline & Universidade Federal do Rio Grande do Sul & 15 & \\
\hline \multicolumn{2}{|r|}{ TOTAL } & 614 & 100 \\
\hline
\end{tabular}

Fonte: Elaboração dos autores com base no Catálogo de Teses e Dissertações - Capes (2018).

Conforme referimos, as regiões Sudeste, Sul, Nordeste e Centro-Oeste destacam-se em face da maior concentração, no período pesquisado, de trabalhos relacionados às categorias 2 e 3. Identificados os estados de São Paulo, Rio Grande do Sul, Bahia e o Distrito Federal como os que concentram o maior número de produções acadêmicas, a Tabela 2 oportuniza verificar o conjunto de instituições a que se filia parte considerável das teses e dissertações mapeadas.

No que se refere ao estado de São Paulo, uma primeira característica a ser pontuada é o número de instituições que, no período, constituíram lócus dos trabalhos acadêmicos identificados na pesquisa. Tal circunstância distingue a região Sudeste das outras três regiões (Sul, Nordeste e Centro-Oeste), notadamente, em face do quantitativo sediado no estado de São Paulo. Ainda assim, do conjunto de 19 instituições paulistas com produção acadêmica identificada com as categorias 2 e 3, sobressaem, em número de produções no estado: a Pontifícia Universidade Católica de São Paulo, com 18,9\% dos trabalhos; a Universidade Estadual Paulista Júlio de Mesquita Filho que, se considerada a soma dos trabalhos vinculados aos diferentes campi, responde por 18,4\% das produções acadêmicas do período; a Universidade Estadual de Campinas e a Universidade Federal de São Carlos, ambas com cerca de $12 \%$ dos trabalhos. 
No Rio Grande Sul, a Universidade Federal do Rio Grande do Sul e a Universidade do Vale do Rio dos Sinos são as que despontam em número de trabalhos publicados entre 1996 e 2015, versando sobre a gestão democrática. Juntas, as duas universidades acumulam cerca de $50 \%$ das produções, no estado, com esse enfoque, o que corresponde a cerca de um quarto das produções de toda a região Sul.

A Universidade Federal da Bahia e a Universidade do Estado da Bahia são as instituições de origem da maior parte dos trabalhos da região Nordeste do país. À primeira, vinculam-se $68,2 \%$ dos trabalhos no estado (14,2\% do total de trabalhos associados às categorias temáticas 2 e 3 , da região Nordeste), e à segunda, vinculam-se $45,4 \%$ das produções acadêmicas.

Por fim, no Distrito Federal, a Universidade de Brasília e a Universidade Católica de Brasília dividem o conjunto das produções identificadas no período. Juntas, as duas instituições respondem, no período, por 48,3\% das produções sobre gestão democrática (da escola pública e/ou da Educação Básica) de toda a região Centro-Oeste. Na mesma região, conforme consta da Tabela 2, também se destaca a Universidade Federal do Mato Grosso, à qual se vinculam 23\% dos trabalhos mapeados.

Ainda que o exame das razões que justificam o destaque desse conjunto de instituições não constitua objetivo do presente estudo, entendemos que fatores como a reconhecida tradição em investigações sobre gestão educacional e a existência de linhas de pesquisa afins, estruturadas no âmbito dos respectivos programas de pós-graduação em Educação, figurem como parte de um conjunto de determinantes maiores da realidade descrita. Entendemos, também, que a projeção do tema 'gestão democrática', ocorrida progressivamente nas últimas três décadas em face de circunstâncias de ordem sócio-política e econômica, tenha sido um ingrediente impulsionador do número de produções nas instituições mencionadas.

E sobre o tema 'gestão democrática' nos trabalhos identificados? Por onde e com quais enfoques esses trabalhos lidam com esse tema? Em linhas gerais, é possível dizer que os trabalhos filiados às categorias temáticas referenciadas na 'gestão democrática' dão lugar a análises que, em maior grau e profundidade, buscam estabelecer conexão entre condições contextuais macro e micro que implicam os fenômenos estudados. Ainda que se considere a especificidade do recorte presente em cada categoria - a escola pública e a Educação Básica segue a marca de esforços no estabelecimento da referida conexão, para o que se vê convocada uma abordagem crítica dos fenômenos estudados. Ganha lugar 
a crítica à política neoliberal e a concorrência de valores mercantis, princípios empresariais e modelos gerenciais dirigidos à escola pública e aos sistemas de ensino.

Sobre os trabalhos reunidos no âmbito da categoria temática 2 - Gestão democrática da escola pública - que constituem $83,9 \%$ do conjunto identificado com a temática alvo do presente estudo, sobressaem leituras e análises referentes a experiências no campo da gestão escolar, notadamente, na forma de estudos de caso, com evidente projeção sobre escolas de Ensino Fundamental. Tais leituras e análises são frequentemente motivadas por circunstâncias políticas de largo alcance - como a implantação de políticas ou programas em nível nacional, estadual ou municipal - ou, mesmo, por circunstâncias de ordem institucional, portanto, identificadas no tempo e no espaço.

Como desdobramento dessa característica geral, verificamos que nesses casos a tendência é pelo posicionamento da 'gestão democrática' na condição de pano de fundo das reflexões tecidas (são raros os trabalhos que a abordam exclusivamente no plano teórico-conceitual, por meio da mobilização de fundamentos políticos, sociológicos e/ou filosóficos), prevalecendo a focalização em alguns objetos ou fenômenos, dentre os quais se destacam: (a) a participação enquanto fenômeno político e/ou enquanto prática, sendo realçadas questões, como a qualidade de condições promotoras, significados atribuídos pelos sujeitos que participam, compromisso político, efetividade de processos, qualidade política viabilizada por espaços e mecanismos institucionalizados de participação e vinculações entre participação e processos decisórios; (b) papel, composição, garantias institucionais, dinâmicas e efetividade da atuação de órgãos colegiados, como os conselhos escolares; e (c) a relação entre gestão democrática e planejamento escolar, representada na figura do projeto político-pedagógico, também expressão da autonomia escolar.

Embora em escala menor, figura também a focalização da gestão democrática da escola pública na interface com políticas de avaliação educacional e de regulação da qualidade, com frequente associação à influência de organismos internacionais; práticas de gestão, especialmente, quanto à atuação do gestor escolar, também examinadas questões relativas à sua formação, função e acesso ao posto; práticas pedagógicas e organização do trabalho escolar; e propostas de integração entre escola e família ou escola e comunidade.

Sobre especificidades dos trabalhos enquadrados na categoria temática 3 - Gestão democrática da Educação Básica, além do fato de o número de trabalhos ser significativamente inferior ao da categoria temática 2 (representa 16,1\% da soma das duas categorias), a abordagem da temática tende a ocorrer em associação com outros temas postos em primeiro plano, frequentemente em torno de programas 
e políticas educacionais endereçados à Educação Básica, dispondo quanto a repercussões e efeitos em redes de ensino, em conjuntos de escolas, no domínio didático-pedagógico, na formação integral dos estudantes, entre outros. Conferem maior presença à temática alguns estudos cujos objetivos focalizam processos decisórios e a organização e dinâmica de espaços e mecanismos de participação em nível de sistemas de ensino e de redes de escolas, como é o caso de colegiados ou conselhos escolares ou municipais e da eleição de diretores. Nesses casos, sobressaem nas pautas investigativas questões afetas à materialização da gestão democrática.

\section{CONSIDERAÇÕES FINAIS}

Conforme buscamos destacar, em paralelo à ascensão da perspectiva democrática de gestão educacional ocorrida nas últimas décadas, da qual também decorre um impulso no número de trabalhos acadêmicos que versam sobre essa perspectiva, têm sido projetadas outras questões acerca da temática. Ao certo, essa projeção também desafia a área e seus pesquisadores à construção de referenciais que possam iluminar práticas no interior das escolas e redes de ensino, ante um cenário que se vem mostrando crescentemente refratário a princípios e práticas democráticos, não sem considerar, conforme adverte Paro (1997), a frequente afirmação da democracia pela via da aparência emprestada.

As muitas denúncias sobre nossa frágil tradição democrática, a prevalência de princípios filiados a uma tradição política conservadora e a frequente instalação de políticas públicas desresponsabilizadas com a democratização, ajudam a dimensionar a correlação de forças entre projetos distintos de sociedade e de educação coexistentes no país, correlação essa que vemos estendida ao domínio da gestão educacional.

Circunstâncias como as aqui descritas, das quais resultam consequências no domínio da gestão educacional, vêm impulsionando a realização de estudos e investigações na área da Educação. O recorte temporal e a modalidade de produção enfocados no presente estudo constituem, a nosso ver, uma mostra importante desse impulso, razão pela qual entendemos que os achados da pesquisa em pauta nos oportunizam condições para apontar algumas tendências atuais em termos de produção do conhecimento a respeito do tema.

Conforme referido, o recorte na 'gestão da educação básica' constituiu, ao longo do período enfocado, um tema recorrente em teses e dissertações da área, cujas pesquisas versaram direta ou indiretamente sobre 'gestão', tendo representado 47\% do conjunto mapeado. De acordo com os dados, uma projeção menos acentuada ficou demarcada entre 1996 e 2012, seguida de um impulso 
significativo no período seguinte, em relação ao qual lançamos a hipótese de que tenha ocorrido em face das medidas em políticas públicas então deflagradas, as quais suscitaram a abertura ou o reforço de frentes de estudos referentes a repercussões no campo da gestão educacional.

$\mathrm{Da}$ focalização dos trabalhos cujas temáticas incluem o tema da democratização, decorreu a identificação de um terço dos trabalhos relacionados à 'gestão da Educação Básica', trabalhos esses enquadrados nas categorias temáticas 'gestão democrática do ensino público' e 'gestão democrática da Educação Básica'. Enquanto o número de publicações de trabalhos da primeira (84\% do conjunto) ocorreu com acentuadas oscilações entre um ano e outro, as publicações relacionadas à segunda categoria, embora em menor número, tenderam à estabilidade ao longo do período.

Também em termos distintivos, o estudo possibilitou verificar que as regiões Sudeste, Sul, Nordeste e Centro-Oeste, nesta ordem, demarcam uma maior concentração de publicações relacionadas ao tema 'gestão democrática', sobressaindo-se, nessas mesmas regiões, um conjunto de estados e de instituições. Uma constatação que nos permite, por um lado, referir a existência de uma tradição local na investigação sobre o tema, e, por outro, supor a existência de linhas de pesquisa afins. De todo modo, importa destacar a existência de desequilíbrios no número de trabalhos originados das diferentes regiões do país, assim como nos estados que as integram, não sem reconhecer o papel fundamental que exercem os programas de pós-graduação das instituições de ensino superior na promoção de pesquisas sobre o tema.

Por fim, quanto aos enfoques constantes nos trabalhos que versam ou incorporam o tema 'gestão democrática', os resultados apontam, como característica geral, a busca pela conexão entre condições contextuais macro e micro que implicam os fenômenos pesquisados, cujos esforços empreendidos nessa direção pautam-se, principalmente, por uma abordagem crítica. A nosso ver, menor incidência de estudos concentrados em dimensões teórico-conceituais do fenômeno da democratização sinaliza a existência de domínios ainda em aberto para investigações.

Consideradas as especificidades em trabalhos filiados a cada uma das categorias identificadas com o tema 'gestão democrática', foi possível constatar que, no caso dos trabalhos relacionados à 'gestão democrática da escola pública', sobressam os estudos de caso, estudos esses frequentemente motivados pela vigência de políticas ou programas governamentais. O fenômeno da participação, os órgãos colegiados e o projeto político-pedagógico constituem os objetos de pesquisa mais correntes. 
Distinguindo-se em algum grau dessa caracterização, os trabalhos filiados à categoria temática 'gestão democrática da Educação Básica' tendem a abordar a gestão democrática em decorrência do enfrentamento de temas específicos e de incidência ampliada. Conforme referido, são exemplos desses temas a efetividade de processos decisórios e a organização e dinâmica de espaços e mecanismos de participação.

Assim posto, com base em uma perspectiva crítico-compreensiva, entendemos que a dinâmica de publicações e o perfil dos trabalhos acadêmicos examinados apontam uma progressiva projeção do tema 'gestão democrática do ensino público na Educação Básica’ apoiada na dimensão política, dimensão essa evocada em estreita relação com a função social da escola pública e a concepção de educação como prática social (FRIGOTTTO, 2003).

Nesse sentido, cientes das condições atuais de circulação da produção existente, tanto a menor frequência de trabalhos em determinadas regiões e/ ou unidades da federação quanto a menor cobertura de determinados temas constituem, a nosso ver, espaços em aberto para a continuidade do curso dessa projeção.

\section{REFERÊNCIAS}

AVELAR, Lúcia. Clientelismo de estado e política educacional brasileira. Educação \& Sociedade, Campinas, ano 17, n. 54, p. 34-50, jan. 1996.

BORDENAVE, Juan E. Diaz. O que é participação? São Paulo: Brasiliense, 1985.

BORON, Atilio A. Estado, capitalismo e democracia na América Latina. 2. ed. Rio de Janeiro: Paz e Terra, 2002.

BRASIL. Constituição da República Federativa do Brasil, 1988. Brasília, DF: Senado Federal, 1988. Disponível em: <http://www.planalto.gov.br/ccivil_03/ constituicao/constituicao.htm>. Acesso em: 19 jun. 2017.

Lei n. 9.394, de 20 de dezembro de 1996. Estabelece as diretrizes e bases da educação nacional. Diário Oficial [da] República Federativa do Brasil, Seção 1, p. 27833-27841, Poder Executivo, Brasília, DF: Imprensa Nacional, 21 dez. 1996. 
Lei n. 13.005, de 25 de junho de 2014. Aprova o Plano Nacional de Educação - PNE e dá outras providências. Diário Oficial União, Edição Extra, n. 120-A, Seção 1, p. 1-8, Poder Executivo, Brasília, DF: Imprensa Nacional 26 jun. 2014.

CHIZZOTTI, Antônio. Pesquisa em ciências humanas e sociais. São Paulo: Cortez, 1991.

COUTINHO, Carlos Nelson. A democracia na batalha das ideias e nas lutas políticas do Brasil de hoje. In: FÁVERO, Osmar; SEMERARO, Giovanni (Org.). Democracia e construção do público no pensamento educacional brasileiro. 2. ed. Petrópolis: Vozes, 2003. p. 11-39.

CURY, Carlos Roberto Jamil. Prefacio. In: OLIVEIRA, Maria Auxiliadora Monteiro (Org.). Gestão educacional: novos olhares, novas abordagens. 2. ed. Petrópolis: Vozes, 2005.

DARDOT, Pierre; LAVAL, Christian. A nova razão do mundo: ensaio sobre a sociedade neoliberal. Tradução Mariana Echalar. São Paulo: Boitempo, 2016.

FAORO, Raymundo. Os donos do poder: formação do patronato político brasileiro. 2 v. 7. ed. São Paulo: Globo, 1987.

FELDFEBER, Myriam. Nuevas y viejas formas de regulación de los sistemas educativos. In: FELDFEBER, Myriam (Org.). Autonomía y governo de la educación: perspectivas, antinomias y tensiones. Buenos Aires: Aique Grupo Editor, 2009. p. 25-50.

FERNANDES, Cleoni Maria Barboza; MOROSINI, Marília Costa. Estado de conhecimento e questões do campo científico. Educação por Escrito, Porto Alegre, v. 5, n. 2, p. 154-164, jul./dez. 2014.

FONSECA, Marília; OLIVEIRA, João Ferreira de. A gestão escolar no contexto das recentes reformas educacionais. Revista Brasileira de Política e Administração em Educação, Porto Alegre, v. 25, n. 2, p. 233-246, maio/ago. 2009. 
FREITAS, Luiz Carlos de. Eliminação adiada: o caso das classes populares no interior da escola e a ocultação da má (qualidade) do ensino. Educação \& Sociedade, Campinas, v. 28, n. 100, p. 965-987, Edição Especial, out. 2007.

FRIGOTTOO, Gaudêncio. Educação e crise do capitalismo real. 5. ed. São Paulo: Cortez, 2003.

IANNI, Octavio. Pensamento social no Brasil. Bauru: EDUSC, 2004.

KRAWCZYK, Nora Ruth. Em busca de uma nova governabilidade na educação. In: OLIVEIRA, Dalila Andrade; ROSAR, Maria de Fatima Felix (Org.). Política e gestão da educação. 2. ed. Belo Horizonte: Autêntica, 2008. p. 61-74.

LAVAL, Christian. A escola não é uma empresa: o neo-liberalismo em ataque ao ensino público. Londrina: Planta, 2004.

NARDI, Elton Luiz. Gestão democrática no contexto dos 20 anos da LDBEN: entre bandeiras, tensionamentos e possibilidades. In: BASTISTA, Neusa Chaves; FLORES, Maria Luiza Rodrigues (Org.). Formação de gestores escolares para a educação básica: avanços, retrocessos e desafios frente aos 20 anos de normatização da gestão democrática na LDBEN. Porto Alegre: Evangraf; Escola de Gestores da Educação Básica, 2016. p. 19-44.

Autonomia da Escola e regulação da qualidade: (pro) posições da Cepal para políticas de gestão da educação na América Latina. In: NARDI, Elton Luiz; ALMEIDA, Maria de Lourdes Pinto de Almeida; VIANA, Isabel Maria Torre Carvalho (Org.). Políticas públicas e regulação da educação: temas em debate. Campinas: Mercado de Letras, 2015. p. 55-86.

NOGUEIRA, Marco Aurélio Nogueira. Democracia participativa. In: GIOVANNI, Geraldo di; NOGUEIRA, Marco Aurélio (Org.). Dicionário de políticas públicas. $2^{a}$ ed. São Paulo: Ed. Unesp; Fundap, 2015. p. 247-252.

OLIVEIRA, Dalila Andrade. Mudanças na organização e na gestão do trabalho na escola. In: OLIVEIRA, Dalila Andrade; ROSAR, Maria de Fatima Felix (Org.). Política e gestão da educação. 2. ed. Belo Horizonte: Autêntica, 2008. p. 127145. 
PARO, Vitor Henrique. Gestão democrática da escola pública. São Paulo: Ática, 1997.

PINHEIRO, Camila Mendes. O Fórum Nacional em Defesa da Escola Pública e o princípio da gestão democrática na Constituição Federal de 1988. 2015, 234 f. Dissertação (Mestrado em Educação)-Universidade Estadual Paulista, Marília, 2015.

WEFFORT, F. C. Por que democracia? 2. ed. São Paulo: Brasiliense, 1984.

ELTON LUIZ NARDI é Doutor em Educação pela Universidade do Vale do Rio dos Sinos (Unisinos). Professor do Programa de Pós-Graduação em Educação da Universidade do Oeste de Santa Catarina (Unoesc). Membro do Grupo de Pesquisa em Educação, Políticas Públicas e Cidadania (GEPPeC). E-mail: elton. nardi@unoesc.edu.br

PAULA FERNANDA SILVEIRA BOIAGO é graduanda em Psicologia pela Universidade do Oeste de Santa Catarina (Unoesc). Membro do Grupo de Pesquisa em Educação, Políticas Públicas e Cidadania (GEPPeC) e bolsista do PIBIC/CNPq. E-mail: e p.fernnandaa@gmail.com 